\title{
A tribute to Dr. Raymond Read
}

\author{
J. Murphy
}

Received: 21 March 2015/Accepted: 25 March 2015/Published online: 1 April 2015

(C) Springer-Verlag France 2015

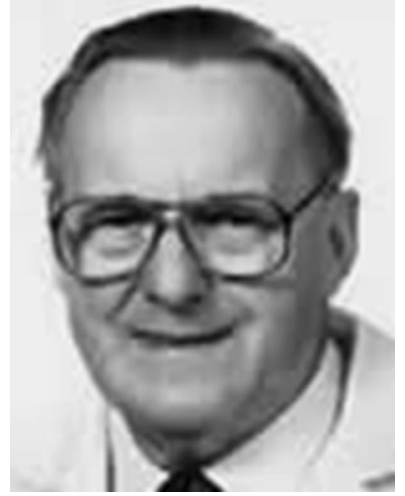

Dr. Raymond Read received his initial education in England where he earned a BA in natural sciences at Cambridge University in 1941. Through a Rockefeller scholarship, he received his MD from the University of Minnesota. He then returned to England and earned his MB $\mathrm{BCh}$ and MA with first class honors at Cambridge. His initial surgical training was at Kings College in London. He then became a fellow in the Royal College of Surgeons of England before returning to the United States where he would obtain graduate training at the Peter Bent Brigham Hospital while serving as the harvard cushing fellow in surgery at Harvard University. He subsequently received an MS in physiology and a Ph.D. in surgery at the University of Minnesota. He became a fellow in the

\footnotetext{
J. Murphy

jmurphymd@earthlink.net

1 Troy, MI, USA
}

American College of Surgery and was boarded in both thoracic and general surgery.

Dr. Read began his surgical career at the University of Minnesota as an Assistant Professor of Surgery. Subsequently, he moved to Wayne State University in Detroit as Associate Professor of Surgery. He then moved to Little Rock, Arkansas where he served as Chief of Surgical Services at the U.S. Veterans Hospital and Professor of Surgery at the University of Arkansas. He retired in 2001 at the age of 77 .

During his career he authored over 500 publications. He was a founding member of the Society of Thoracic Surgeons and the American Hernia Society. He was a member of over two dozen professional societies and served as President of the Association of Veterans Administration Surgeons, the Southwestern Surgical Association, and the American Hernia Society.

Dr. Read was the recipient of many awards, too numerous to mention, but including the Distinguished Service Award from the Association of Veterans Administration Surgeons and induction into the University of Arkansas College of Medicine Hall of Fame. His certification from The National Hole-in-One Association was a highlight.

He was a pioneer in surgery, especially in his chosen field of herniology. He was referred to as "Once a sinner and now a saint" by Dr Volker Schumpelick for his work which demonstrated that indeed hernia defects were the result of abnormal collagen, a concept that took many years to be fully accepted.

Dr. Read always exhibited a contagious zest for life and a keen intellect, and he lived his life to the fullest, never wasting a minute but always having time for his family and never failing to offer help to his fellow man. He was a kind and gentle man, a giant in his field, and 
a true renaissance man. It is not beyond the realm of imagination that he might be sitting with his colleagues who have passed before him discussing any number of subjects and for him to conclude the discussion by declaring "And What Do You think About That?" followed by a hardy laugh!

He will be sorely missed and we have lost one of the truly great ones. 